\title{
Process Water Recirculation during Hydrothermal Carbonization of Waste Biomass: Current Knowledge and Challenges
}

\author{
Antonio Picone, Maurizio Volpe *(D) and Antonio Messineo (D) \\ Faculty of Engineering and Architecture, University of Enna KORE, 94100 Enna, Italy; \\ antonio.picone@unikorestudent.it (A.P.); antonio.messineo@unikore.it (A.M.) \\ * Correspondence: maurizio.volpe@unikore.it
}

check for updates

Citation: Picone, A.; Volpe, M.;

Messineo, A. Process Water

Recirculation during Hydrothermal Carbonization of Waste Biomass: Current Knowledge and Challenges. Energies 2021, 14, 2962. https:// doi.org/10.3390/en14102962

Academic Editor: Alberto Coz

Received: 21 April 2021

Accepted: 18 May 2021

Published: 20 May 2021

Publisher's Note: MDPI stays neutral with regard to jurisdictional claims in published maps and institutional affiliations.

Copyright: (c) 2021 by the authors. Licensee MDPI, Basel, Switzerland. This article is an open access article distributed under the terms and conditions of the Creative Commons Attribution (CC BY) license (https:// creativecommons.org/licenses/by/ $4.0 /)$.

\begin{abstract}
Hydrothermal carbonization (HTC) is considered as an efficient and constantly expanding eco-friendly methodology for thermochemical processing of high moisture waste biomass into solid biofuels and valuable carbonaceous materials. However, during HTC, a considerable amount of organics, initially present in the feedstock, are found in the process water (PW). PW recirculation is attracting an increasing interest in the hydrothermal process field as it offers the potential to increase the carbon recovery yield while increasing hydrochar energy density. PW recirculation can be considered as a viable method for the valorization and reuse of the HTC aqueous phase, both by reducing the amount of additional water used for the process and maximizing energy recovery from the HTC liquid residual fraction. In this work, the effects of PW recirculation, for different starting waste biomasses, on the properties of hydrochars and liquid phase products are reviewed. The mechanism of production and evolution of hydrochar during recirculation steps are discussed, highlighting the possible pathways which could enhance energy and carbon recovery. Challenges of PW recirculation are presented and research opportunities proposed, showing how PW recirculation could increase the economic viability of the process while contributing in mitigating environmental impacts.
\end{abstract}

Keywords: waste biomass; hydrothermal carbonization; hydrochar; process water recirculation; energy recovery

\section{Introduction}

Environmental pollution and global warming threaten the world equilibrium and require a new and sustainable approach to the strategies implemented in the different productive systems. Improving the environmental sustainability of production systems requires the access to a scenario of energy sources as wide and varied as possible, promoting the use of alternative and renewable resources in a circular economy perspective. The unstoppable increase of population, especially in the metropolitan areas, has led to the increase of organic waste production, thereby raising the environmental issues related to their correct handling and disposal. Organic wastes, instead of representing a cost for the community, could represent a valuable resource, if properly used as feedstock for ecofriendly energy conversion systems. Renewable energy systems, as a part of a sustainable development, bring environmental, energetic, and economic benefits such as the reduction of greenhouse gas, a reliable energy supply, and economic savings [1]. The most promising routes for energy recovery from biomass wastes include biochemical and thermochemical technologies [2-5]. Biological methods such as anaerobic digestion are widely used to convert organic waste into gaseous biofuel; however, the correct implementation of biological processes need high investment and maintenance costs, while needing specific composition of feedstock to avoid process inhibition and increase bio-methane yields [6,7]. The dry thermochemical methods of biomass upgrading to bio-fuels and valuable carbonaceous 
materials (e.g., torrefaction, pyrolysis and gasification), while ensuring high energy densification and fast reaction rate, are not energetically (and thus economically) sustainable when treating high moisture biomass residues.

In fact, the need of a drying pretreatment negatively affects the overall process efficiency [8-11]. For these reasons, wet thermochemical conversion technologies as hydrothermal processes gained increasingly more attention in the last decades, demonstrating to be very promising conversion routes for wet biomass wastes to energy dense bio-fuels and valuable materials. In particular, hydrothermal carbonization (HTC) was demonstrated to be efficient for very high moisture residues as sewage and agro-industrial sludge [12-14]. In hydrothermal processes, the organic residue is subjected to a thermal process at autogenous pressure of saturated steam in the presence of sub-critical or supercritical water [15]. Hydrothermal treatment can be classified on the basis of the selected processing temperature and as a result the predominant yield nature: hydrothermal carbonization (HTC), liquefaction (HTL), and gasification (SCWG). During HTL, biomass is processed at $300-350{ }^{\circ} \mathrm{C}$ and 150-200 bar for the production of a liquid 'biocrude' [16,17], while, during SCWG, biomass is treated at temperatures reaching $600-700{ }^{\circ} \mathrm{C}$ in supercritical water condition, with the aim to obtain gas products (mainly hydrogen and carbon dioxide) $[18,19]$. The HTC process occurs, in general, at mildest conditions compared to other hydrothermal conversions. Most frequently, temperatures between 180 and $250{ }^{\circ} \mathrm{C}$, autogenous pressures of up to approximately 40 bar and reaction times between few minutes and several hours are applied. HTC simulates the long-time natural process of converting biomass to coal, producing a carbonaceous material, commonly named 'hydrochar', in a very short time (typically no longer than 6-12 h) and at high yields [20-24]. The highly dense carbonaceous material derived could be used in a wide range of applications including energy $[25,26]$, environment (HTC has been successfully used as a pre-treatment for the production of activated carbons as water remediation agents) [27,28], soil improvement [29], and nutrients recovery fields [30-32].

When compared to the dry thermochemical conversion routes, HTC process ensures several advantages such as energy saving, high conversion efficiency due to the catalytic effect of water, relatively low operating temperatures, and the removal inorganic compounds and thus low ash content during combustion of the solid product [33,34]. During HTC treatment, water has the crucial role of solvent and catalyst. At high temperatures and pressures, water promotes chemical bond breaking to produce high water soluble volatile organic acids (i.e., acetic, formic, and levulinic acid) leaving more stable solid aromatic compounds in character $[35,36]$. Under HTC reaction conditions, dehydration and decarboxylation reactions lead to a substantial reduction of oxygen content, which is one overall objective of producing fuels from biomass [37]. Together with the main solid product, the HTC process yields a liquid by-product, called process water (PW), and a variable but typically small amount of gases mainly composed of $\mathrm{CO}_{2}$ [38]. When the biomass is treated under hydrothermal conditions, organic water soluble substances (as organic acids) concentrate in the liquid phase, resulting in extensive carbon and energy losses. Detailed investigations have shown that the PW mainly consists of organic acids (formic, acetic, lactic, and propionic), sugars (glucose, fructose, and xylose), furans (furfural and 5-HMF), and phenols [39-42]. Reuse and valorization of post-processing water represent one of the most relevant challenges to make the HTC process more economically viable and environmentally friendly. The recirculation of PW as reaction medium of the hydrothermal process is a promising approach, which, on the one hand, could minimize the hydrothermal wastewater discharge and, on the other hand, could increase the yield of solid biofuel and thus, carbon recovery [43].

Organic compounds concentrated in the liquid phase could promote condensation reactions to yields solid carbonaceous material $[44,45]$. These reactions could result in reconversion of the organic intermediates and their subsequent interaction with the biomass during the recirculation steps, thereby modifying the evolution mechanism and characteristics of the resulting hydrochar [46]. In a view of large-scale applications, the water 
demand may exceed hydrochar profitability in terms of production costs; therefore, the recirculation strategy could significantly reduce the water consumption [47]. Reuse of PW could also be an efficient method of heat recovery, improving the overall energy efficiency of the process. Although the PW recycling can be a potential method to valorize the liquid residual fraction of the process, more investigations are needed to evaluate the application of products generated after recirculation steps, the real effects on the environment, and the properties of HTC products for different substrates at various operating conditions. As an alternatively to recirculation, different approaches are discussed in the literature for the PW treatment. Wet oxidation is used to remove organic compounds in the liquid phase: oxygen or air reacts with the organic compounds to produce carbon dioxide and water; thus, the treatment may improve the biodegradability of wastewater components $[48,49]$. PW may be fermented in an anaerobic digestion plant: the high share of organic matter in the HTC water allows for a valorization through biological degradation [50-52]. This paper reviews the HTC PW recirculation strategy as a potential path to improve energy recovery from waste biomasses. More specifically, the effects of PW recirculation on the mass yield, energy properties, and composition of the hydrochars and on the chemical evolution of the aqueous phase were analyzed in detail, focusing on HTC reactions promoted during recirculation steps. The influence of process parameters on PW recirculation performances is also discussed according to the biomass treated. Finally, challenges and research opportunities are proposed in order to identify the future directions which could make hydrothermal carbonization more economically feasible and environmentally safe by valorizing the residual liquid fraction of the process.

\section{Effect of PW Recirculation on Hydrochar Properties}

\subsection{Effect on the Mass Yield}

The change in the mass yield (MY) of hydrochars, produced from different waste organic residues, after PW recirculation is shown in Table 1. Recirculation of process water led to an increase in MY of $7 \%$ on average. The maximum value was observed for the substrate paper. In this case, after recirculation, the MY increased by approximately $20 \%$. Many chemical reactions occur during hydrothermal carbonization. The formation mechanism of hydrochar includes hydrolysis, dehydration, decarboxylation, condensation, polymerization, and aromatization [53-55]. They do not represent consecutive reaction steps, but rather form a parallel network of different reaction paths. Lignocellulosic bio-wastes are mainly composed of cellulose, hemicelluloses, and lignin polymers [56]. Hemicellulose is more sensitive to temperature and could rapidly depolymerize to polysaccharides with lower molecular mass, at temperatures close to $180{ }^{\circ} \mathrm{C}$ [57]. Hydrolytic reactions lead to various monosaccharides units such as hexoses and pentoses [58]. In a similar way, cellulose is hydrolyzed at higher temperatures $\left(200-230^{\circ} \mathrm{C}\right)$ [59] to form other sugars (e.g., glucose). Soluble lignin is hydrolyzed into phenolic compounds while not soluble lignin (most of the lignin), together with un-hydrolyzed cellulose and hemicelluloses, form the hydrochar matrix through a solid-solid conversion mechanism [60].

The hydrolysis products subsequently undergo a series of reactions as isomerization, dehydration, and fragmentation producing key intermediates such as 5-HMF and furfurals and their derived products. The intermediates in the decomposition process also produce organic acids including acetic, lactic, propionic, levulinic, and formic acids which lower the $\mathrm{pH}$ of the reaction medium [61-63]. Organic acids, produced by dehydration of intermediates, accumulate in PW and could catalyze and promote some HTC reactions when the aqueous medium is recirculated. The acidic conditions could also favor the further degradation of biomass into monosaccharides producing more water soluble intermediates (for example, the dehydration of glucose into HMF) [64,65].

A large number of intermediates with significant reactivity could be involved in condensation and polymerization reactions to form organic compounds which are converted in solid phase aromatic clusters, and aggregated into carbonaceous microspheres [77]. Most of the microspheres precipitate on hydrochar surface contributing to its mass growth, while 
the remaining amount is suspended in the aqueous medium [46]. Thus, the organic acids in the liquid phase formed during the HTC process, if recirculated, could act as a catalyst and promote dehydration reactions which significantly boost the carbonization process, contributing to hydrochar production through condensation and back-polymerization reactions $[46,66,67]$. Moreover, organic acids could also directly participate in the formation of hydrochars through condensation reactions and the subsequent precipitation on hydrochar matrix. Alternatively, other authors $[68,75]$ suggested that the recirculated PW might lead to a resistance to diffusion of the degraded soluble fragments from the particle surface of biomass to the solution, causing an increased hydrochar yield. The literature reviewed suggests that the number of PW recirculation steps influences the hydrochar formation process according to the feedstock treated and the operating conditions. It was seen that the hydrochar yield does not follow a typical trend during recirculation steps; thus, further investigations are required to understand how the number of recycle steps affects the hydrochar mass yield.

Table 1. Effect of process water recirculation on mass yield (MY) and HHV of hydrochars produced from different residual biomasses, and on $\mathrm{pH}$ and total organic carbon (TOC) of HTC liquid phase. For MY and HHV, reference value of HTC step with deionized water and maximum value during recirculation steps are reported. For $\mathrm{pH}$ and TOC, reference value of HTC step with deionized water and value of last recirculation step are reported.

\begin{tabular}{|c|c|c|c|c|c|c|c|c|c|}
\hline Feedstock & $\begin{array}{c}\text { Temperature } \\
\left({ }^{\circ} \mathrm{C}\right)\end{array}$ & RT $^{1}$ & $\mathrm{~B} / \mathbf{W}^{2}$ & $\mathbf{R S}^{3}$ & $\begin{array}{c}\text { MY }^{4} \\
(\%)\end{array}$ & $\begin{array}{l}\mathrm{HHV}^{5} \\
\text { (MJ/Kg) }\end{array}$ & $\mathrm{pH}$ & $\begin{array}{c}\text { TOC }^{6} \\
(\mathrm{~g} / \mathrm{L})\end{array}$ & References \\
\hline Cornstalk (CK) & 220 & $2 \mathrm{~h}$ & 0.2 & 4 & $55.9-66.2$ & $22.7-23.3$ & $3.7-3.9$ & $11.7-29.1$ & [46] \\
\hline BSG $^{7}$ & 200 & $2 \mathrm{~h}$ & 0.13 & 2 & $59.0-60.4$ & $28.7-27.9$ & $4.5-4.3$ & $17.0-15.1$ & [66] \\
\hline BSG & 200 & $4 \mathrm{~h}$ & 0.13 & 2 & $54.6-51.3$ & $28.5-29.0$ & $4.6-4.5$ & $21.8-12.4$ & {$[66]$} \\
\hline BSG & 220 & $2 \mathrm{~h}$ & 0.13 & 2 & $56.0-70.2$ & $29.4-30.5$ & $4.6-4.5$ & $15.6-28.5$ & [66] \\
\hline BSG & 220 & $4 \mathrm{~h}$ & 0.13 & 2 & $54.2-65.9$ & $30.5-31.7$ & $4.7-4.5$ & $14.9-20.4$ & [66] \\
\hline Laminaria (LM) & 220 & $2 \mathrm{~h}$ & 0.05 & 12 & $13.3-17.8$ & $18.4-22.7$ & $4.8-5.6$ & $\mathrm{Na}^{8}$ & [67] \\
\hline Loblolly pine (LP) & 200 & $5 \mathrm{~min}$ & 0.2 & 9 & $82.1-90.0$ & $20.6-20.9$ & $3.4-3.3$ & $11.7-37.8$ & [68] \\
\hline Loblolly pine (LP) & 230 & $5 \mathrm{~min}$ & 0.2 & 9 & $75.0-82.9$ & $21.5-21.8$ & $2.9-3.0$ & $18.3-29.4$ & [68] \\
\hline Loblolly pine (LP) & 260 & $5 \mathrm{~min}$ & 0.2 & 5 & $60.0-69.3$ & $25.0-25.3$ & $2.8-2.9$ & na & [68] \\
\hline SPW $^{9}$ & 220 & $1 \mathrm{~h}$ & 0.2 & 4 & $60.4-66.3$ & $23.0-23.7$ & na & na & [69] \\
\hline MGW $^{10}$ & 180 & $5 \mathrm{~h}$ & 0.15 & 10 & $81.0-85.0$ & $25.4-26.6$ & $4.6-4.5$ & $21.4-30.9$ & [70] \\
\hline MGW & 220 & $5 \mathrm{~h}$ & 0.15 & 10 & $60.0-70.0$ & $28.8-29.8$ & $4.3-4.5$ & $19.6-22.7$ & [70] \\
\hline Miscanthus (MS) & 260 & $5 \mathrm{~min}$ & 0.17 & 10 & $47.0-57.0$ & $26.1-26.6$ & $2.7-2.7$ & $28.6-59.0$ & [71] \\
\hline Paper (PP) & 200 & $16 \mathrm{~h}$ & 0.1 & 4 & $56.4-75.8$ & $21.7-20.0$ & $2.7-2.8$ & na & [72] \\
\hline Chlorella $(\mathrm{CH})$ & 220 & $4 \mathrm{~h}$ & 0.1 & 4 & $20.5-26.7$ & $30.8-32.1$ & na & $27.9-88.7$ & [73] \\
\hline Soybean straw (SS) & 220 & $4 \mathrm{~h}$ & 0.1 & 4 & $47.7-54.7$ & $21.6-22.5$ & na & $13.2-32.7$ & [73] \\
\hline Poplar wood (PW) & 220 & $4 \mathrm{~h}$ & 0.2 & 4 & $60.1-61.2$ & $25.0-26.2$ & $3.4-3.4$ & $17.4-39.2$ & [74] \\
\hline Grape pomace (GP) & 225 & $10 \mathrm{~min}$ & 0.25 & 3 & $64.3-75.2$ & $25.5-25.9$ & $3.9-4.1$ & $12.1-26.3$ & [75] \\
\hline Orange pomace (OP) & 225 & $30 \mathrm{~min}$ & 0.25 & 3 & $51.6-57.5$ & $24.0-23.7$ & $3.8-3.9$ & $32.1-57.9$ & [75] \\
\hline Poultry litter (PL) & 225 & $15 \mathrm{~min}$ & 0.25 & 3 & $53.0-62.4$ & $21.2-20.8$ & $5.5-5.7$ & $27.4-49.7$ & [75] \\
\hline Lemon peel (LPW) & $\begin{array}{l}180 \\
220\end{array}$ & $1 \mathrm{~h}$ & 0.2 & 2 & $50.1-55.9$ & $22.4-22.2$ & $3.9-4.0$ & $16.0-20.0$ & [76] \\
\hline Lemon peel (LPW) & 220 & $1 \mathrm{~h}$ & 0.2 & 2 & $49.2-51.2$ & $24.4-24.7$ & $4.4-4.5$ & $13.3-17.8$ & [76] \\
\hline Lemon peel (LPW) & 250 & $1 \mathrm{~h}$ & 0.2 & 2 & $40.9-42.5$ & $26.7-27.2$ & $4.7-4.7$ & $9.7-18.0$ & [76] \\
\hline
\end{tabular}

\subsection{Effect on $H H V$ and Energy Yield}

One of the main benefits of the HTC of waste biomass is to produce an energy dense, high quality, solid fuel, showing increased HHV values to respect the starting biomass [68]. Table 1 demonstrates that PW recirculation during the HTC process has the potential to increase the HHV of hydrochars $[45,61,64,67,68]$. The maximum HHV increase was observed for the feedstock laminaria; the recirculation of PW led to a HHV increase of almost 20\%. The slight energy densification of hydrochars could be explained as follows. Organic acids in PW tend to accelerate the conversion rate of the feedstock, particulary the dehydration of hydrolytic products of hemicellulose and cellulose, to form water soluble intermediates [57]. These materials could polymerize and increase the availability of solid 
particles with high energy density [46]. The increase in solid microparticles polymerized from the organic matter of PW leads to an increase in the carbon content of hydrochars and thus their energy content. In other studies [66,68,75], HHV remained almost unchanged or slightly decreased. Organic acids and some sugars produced during the hydrothermal process are oxygenated and have lower HHV than deoxygenated biocarbon [68]; thus, any deposition of these substances on the hydrochar surface could balance the increase in carbon content, leading to hydrochars showing unchanged or decreased HHV. Moreover, in some cases, the total organic acid concentration could be too low to influence the elemental composition and thus the HHV [70]. These findings demonstrate that PW recirculation effects on hydrochars is strictly related to the nature and preparation of feedstock, the hydrothermal conditions, and the design of reactor.

Energy yield (EY) is another parameter which measures the energy recovered from hydrothermally treated biomass, and can be calculated as reported in Equation (1).

$$
\mathrm{EY}=\mathrm{MY} \times \mathrm{EDR}
$$

EDR is the energy densification ratio defined as $\mathrm{HHV}_{\mathrm{HCdb}} / \mathrm{HHV}_{\mathrm{Rdb}}\left(\mathrm{HHV}_{\mathrm{HCdb}}\right.$ and $\mathrm{HHV}_{\mathrm{Rdb}}$ are the higher heating values of hydrochar and raw feedstock, respectively). Figure 1 reports the comparison of energy yields and carbon recovery values obtained from HTC steps with deionized water and recirculated PW as a solvent (carbon recovery was evaluated as carbon mass in the hydrochar/carbon mass in feedstock on a dry basis). For each feedstock, the increased hydrochar yield, after recirculation steps, led to a noticeable increase of energy yield and carbon recovery. These trends show that PW recirculation enhances the carbonization process and allows to recover a considerable amount of carbon, and thus energy, which otherwise would be "lost" in the aqueous reaction medium.

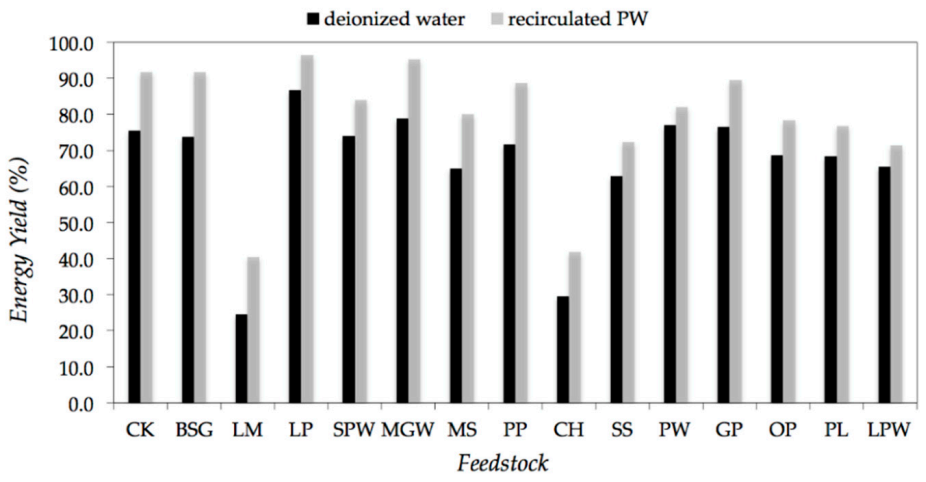

(a)

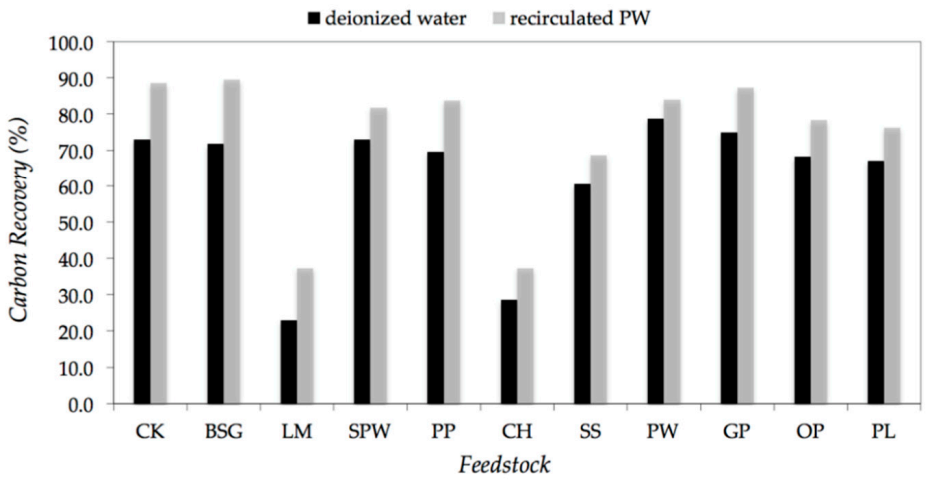

(b)

Figure 1. Effect of process water recirculation on energy yield (a) and carbon recovery (b) from biomass. 


\subsection{Effect on Chemical Composition}

Proximate and elemental compositions of hydrochars, obtained from HTC steps with deionized water and recirculated PW as a solvent, are reported in Table 2. After recirculation steps, as it can be observed, the hydrogen $(\mathrm{H})$ and nitrogen $(\mathrm{N})$ contents remained almost unchanged, as commonly observed during HTC of lignocellulosic waste biomass [59]. Differently, carbon (C) and fixed carbon (FC) contents increased while oxygen $(\mathrm{O})$ and volatile matter $(\mathrm{VM})$ contents decreased $[46,66,67,73]$. These findings confirm that the hydrochars are further converted into solid fuel by HTC with recirculated PW. As mentioned in the previous sections, the changes in the chemical composition of hydrochars after recirculation steps are primarily due to the catalytic role of organic acids concentrating in recycled PW. The increasing carbon content and decreasing oxygen content demonstrate that deoxygenation is promoted by PW recirculation [43]. Sugars derived from the hydrolysis of hemicellulose and cellulose are dehydrated into intermediates such as $\mathrm{HMF}$ which are further dehydrated and decarboxylated, producing $\mathrm{H}_{2} \mathrm{O}$ and $\mathrm{CO}_{2}$ [78]. Besides, during condensation and polymerization of furfurals, further water is eliminated, causing a remarkable reduction of the oxygen content in the solid products [66].

Table 2. Effect of process water recirculation on hydrochars' proximate and elemental composition. For each parameter, reference value of HTC step with deionized water and value of recirculation step corresponding to maximum $\mathrm{C}$ (FC) content are reported. Operating conditions (temperature, RT, B/W, RS) are reported in Table 1.

\begin{tabular}{|c|c|c|c|c|c|c|c|c|}
\hline \multirow{2}{*}{ Feedstock } & \multicolumn{3}{|c|}{ Proximate Composition (wt $\%$ d.b.) } & \multicolumn{4}{|c|}{ Elemental Composition (wt $\%$ d.b.) } & \multirow{2}{*}{ References } \\
\hline & VM & Ash & FC & $\mathrm{C}$ & $\mathbf{H}$ & $\mathbf{N}$ & $\mathbf{O}$ & \\
\hline CK & $64.6-61.4$ & $2.8-5.2$ & $31.2-32.2$ & $56.2-57.6$ & $5.8-5.7$ & $1.8-1.9$ & $33.4-29.5$ & [46] \\
\hline BSG & $70.7-69.3$ & $4.5-3.8$ & $24.8-26.91$ & $61.9-60.8$ & $8.0-7.7$ & $3.8-4.0$ & $21.3-22.8$ & [66] \\
\hline BSG & $69.5-67.7$ & $4.7-4.9$ & $25.8-27.5$ & $62.5-62.7$ & $7.6-7.9$ & $3.9-4.0$ & $20.8-20.1$ & {$[66]$} \\
\hline BSG & $66.3-65.8$ & $4.1-4.6$ & $29.6-29.6$ & $64.1-65.2$ & $7.7-8.1$ & $4.1-4.2$ & $19.4-17.3$ & {$[66]$} \\
\hline BSG & $64.0-64.9$ & $4.6-4.5$ & $31.4-30.6$ & $65.5-67.7$ & $8.1-8.3$ & $4.1-4.3$ & $17.2-14.8$ & [66] \\
\hline LM & $\mathrm{Na}^{1}$ & na & na & $45.9-55.7$ & $6.3-6.7$ & $3.6-4.2$ & $34.9-27.5$ & [67] \\
\hline SPW & $65.4-64.5$ & $6.6-6.8$ & $28.0-28.7$ & $58.0-59.2$ & $5.4-5.5$ & $0.2-0.2$ & $29.6-28.2$ & [69] \\
\hline PP & na & na & na & $54.7-49.9$ & 5.7-6.1 & na & $39.4-44.1$ & [72] \\
\hline $\mathrm{CH}$ & na & na & na & $66.5-68.5$ & $7.6-8.0$ & $6.5-6.5$ & $12.4-11.5$ & [73] \\
\hline SS & na & na & na & $52.1-53.5$ & $5.3-5.5$ & $3.0-3.3$ & $24.7-22.9$ & [73] \\
\hline PW & na & $0.7-0.4$ & na & $62.2-65.2$ & $5.6-5.5$ & $0.2-0.1$ & na & [74] \\
\hline GP & $41.9-43.3$ & $2.9-2.37$ & na & 61.6-61.9 & 5.9-6.1 & $1.8-2.1$ & $27.7-27.4$ & [75] \\
\hline $\mathrm{OP}$ & $38.0-41.0$ & $5.5-7.6$ & na & $56.6-58.3$ & $5.4-5.1$ & $2.4-2.8$ & $29.3-26.0$ & [75] \\
\hline PL & $39.2-38.1$ & $11.3-11.7$ & na & $51.8-51.0$ & $5.4-5.3$ & $3.9-4.2$ & $27.6-27.9$ & [75] \\
\hline LPW & $65.3-62.6$ & $2.3-3.0$ & $32.4-34.4$ & na & na & na & na & [76] \\
\hline LPW & $58.1-58.1$ & $3.1-3.2$ & $38.8-38.7$ & na & na & na & na & [76] \\
\hline LPW & $50.5-51.7$ & $3.2-3.3$ & $46.3-45.1$ & na & na & na & na & [76] \\
\hline
\end{tabular}

${ }^{1}$ na $=$ not available.

As well reported in the literature, hydrochars often exhibit lower ash content than raw feedstock $[34,79,80]$. Alkali metals such as $\mathrm{Na}$ and $\mathrm{K}$ and other inorganic elements which are commonly found in considerable quantities in the raw feedstock are largely removed from the solid phase during HTC [21]. However, the ash content of hydrochars gradually increased with the number of PW recirculation steps. This may be a result of an increased concentration of non-leachable inorganics into PW [76]. For the reasons stated above, PW recirculation during HTC demonstrates to be a suitable way to enhance the carbonization process of biomass into a solid biofuel, improving the characteristics of hydrochars, which could be considered a potential added renewable energy source in coal co-firing plants [81]. Figure 2 shows the hydrochar production mechanism during HTC with recycled PW. 


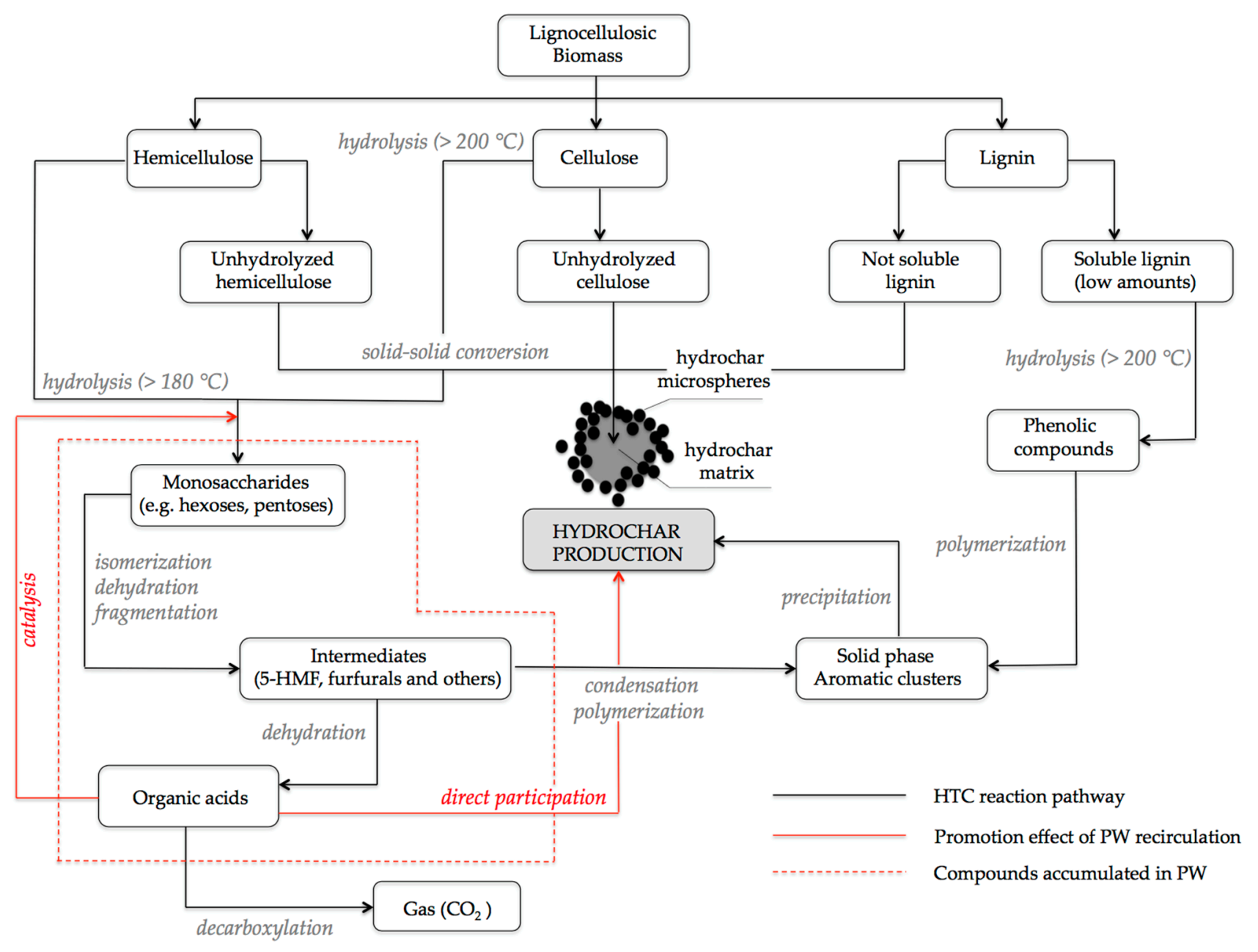

Figure 2. Hydrochar production during HTC process with recirculated PW (summarized from $[43,44,46,57])$.

\section{Effect of PW Recirculation on Liquid Phase Properties}

Aqueous reaction medium collected after HTC of lignocellulosic biomass shows a $\mathrm{pH}$ in the acidic range, typically between 4 and 6 [39]. Although organic acid production from dehydration of sugars could be promoted during recirculation, the recycled PW showed a slight increase of $\mathrm{pH}$ (Table 1). This trend could be explained by the potential increase of inorganic ion (such as alkali metals) concentration in the recirculated liquid phase. Indeed, during the HTC process, the most of inorganics elements present in the inorganic extractives of raw feedstock tend to leach towards the aqueous phase [21]. TOC values showed a noticeable increase after PW recirculation steps (Table 1), obviously due to the increase of organic soluble compound concentration at each step, in addition to those produced in the previous cycle. However, this trend was shown to decrease with the increase of the number of recycling steps. This behavior can be explained with the reactions of condensation and back-polymerization of soluble organics occurring in a greater extent with the increase of their concentration in PW [46,67]. In order to examine the chemical composition and evolution of the recycled process water, concentrations of selected organic compounds accumulated in PW (e.g., organic acids, HMF, furfurals, phenols) were measured by high performance liquid chromatography analysis [66,74].

It was observed that the concentration of the organic acids increased during the first recirculation steps and thereafter, remained almost constant [46]. According to the processing conditions such as the severity of reaction, some acids appeared to be more stable while others increased until equilibrium was reached during the recirculation cycles. During the HTC of green waste, Kochermann et al. [70] found that acetic acid increased significantly 
as the temperature increased, probably because a higher temperature enhances biomass hydrolysis. The concentration equilibrium was not reached in contradiction with a study by Stemann et al. [74] who observed a fast equilibrium of acetic acid concentration from the HTC of poplar wood. In contrast to acetic acid, formic acid was found in higher concentrations at lower temperatures, but at lower concentrations compared to those of acetic acid [70]. These considerations are also strictly related to the nature of the treated feedstock. The dynamic state of the equilibrium of acids, reached after the recirculation steps, probably contributed to maintain more or less stable $\mathrm{pH}$ values. The intermediate substances as HMF and furfurals behaved differently. It was seen that their concentration rapidly declined after PW recirculation. This trend is probably due to the intermediates' participation to produce new solid phase particles by condensation and re-polymerization reactions [46,74].

Phenols are the main product of lignin degradation and could remain stable in a subcritical water environment. Similarly to the organic acids, they accumulated in PW and reached equilibrium [46].

Beside the organics described, many others compounds are found in PW. They consists of unidentified monomeric substances and presumably a major fraction is of macromolecular nature $[74,82]$. The concentration of these molecules was found to rise to a lesser extent than organic acids [74] or to be decreased [46], suggesting that they can probably take part in polymerization reactions as well, contributing to hydrochar production. A relative rise of organic acids, during PW recirculation, compared to more reactive compounds may facilitate the anaerobic and aerobic treatment of the liquid phase. In particular, formic and acetic acid can be metabolized quickly to methane by methanogenesis [74]. HTC PW is a very complex mixture and its composition is largely unknown. The final concentration of organics in the liquid medium significantly depends upon the rate at which they were produced and the rate at which they took part in hydrochar production, and thus by the nature of the feedstock and HTC reaction conditions. A detailed knowledge of the chemical composition and reactivity of the species in HTC PW is still lacking and thus, further and in-depth kinetic studies are required.

\section{Influence of Operating Conditions on PW Recirculation}

Temperature is considered as the main factor that affects HTC reactions and enhances biomass conversion efficiency by providing more energy for breaking the intermolecular bonds in the feedstock [83-85]. Higher conversion rates can be achieved as well at longer retention times [86-88]. Temperature, residence time, and, to a lesser extent, solid load can be used to measure the severity of the process [23,88,89]. Picone et al. [76] studied the effects of temperature on hydrochars properties during the HTC of lemon peel waste with recycled PW. The authors observed that the increase in hydrochar yield obtained after recirculation steps at $180^{\circ} \mathrm{C}$ was more pronounced compared to that obtained at $220^{\circ} \mathrm{C}$ and $250{ }^{\circ} \mathrm{C}$. At higher temperatures, organic acids derived from dehydration of intermediate compounds could be more involved in decarboxylation reactions to form further gaseous products [90]. This could lead to a lower acid concentration in the spent liquid medium; therefore, hydrolysis of biomass polymers could not be promoted sufficiently to increase the availability of soluble intermediates for condensation and re-polymerization reactions. Moreover, at higher temperatures, the unstable intermediates themselves could form more rapidly new solid phase particles which aggregate to the hydrochar matrix; hence, lower amounts of reactive compounds remain in the liquid phase $[62,91]$.

On the contrary, Kochermann et al. reported an increase in hydrochar yield of $4 \%$ at $180{ }^{\circ} \mathrm{C}$ and of $10 \%$ at $220^{\circ} \mathrm{C}$, after recirculation steps from HTC of green waste, thus testifying to the important role played by the nature of the starting biomass. The authors suggested that these results could be related to the stronger increase of total carbon found in PW at higher temperatures. The increase of soluble carbonaceous particles is attributed to a higher degree of feedstock decomposition at $220^{\circ} \mathrm{C}$, mainly caused by the hydrolysis of hemicellulose and cellulose [70]. Challenges in determining the exact mechanisms driving the changes of hydrochar mass yields with temperature are related to the complexity and 
mutual influence of the process variables involved, as the nature of the feedstock, residence time, and number of recirculation steps. The effect of residence time on the HTC PW recirculation process when compared to conventional HTC is similar. At longer residence times, the organics and less stable compounds in solution react, increasing solid yields [43]. Stemann et al. [74] and Wang et al. [46] found that the HMF concentration decreased after recirculation steps with residence times of $4 \mathrm{~h}$ and $2 \mathrm{~h}$ respectively, to form new solid phase structures, while Kambo et al. [71] reported a HMF content stable after 10 recirculation steps and a reaction time of $5 \mathrm{~min}$; thus, very short residence times seem to be insufficient to allow an increase of HMF concentration capable to induce its conversion into hydrochar. In summary, it appears clear that the effect of process parameters on HTC products during PW recirculation strictly depends on the type of the treated feedstock and thus on the nature and concentrations of soluble organics concentrated in the liquid phase. Further and more systematic investigations are needed to detect the influence of the single biomass macro-component on hydrochar formation mechanisms during HTC PW recirculation.

\section{Challenges and Research Opportunities}

In order to decrease water footprint and maximize energy recovery, recycling the process water as reaction medium during the HTC of waste biomass seems to be a promising strategy. The reactive substances derived from the degradation of biomass macrocomponents during HTC concentrate in the PW, influencing the hydrochar mechanism formation improving its mass yield and energy properties during recirculation steps. However, there are only few studies in the literature that deal with PW recirculation and further investigations should fill existing knowledge gaps of PW valorization by recirculation. Challenges and future research directions for PW recirculation are outlined in Figure 3. The literature reviewed suggests that the effect of PW recirculation on hydrochar production strictly depends on the type of feedstock and hydrothermal conditions. One of the main challenges of PW recirculation during HTC is the optimization of process parameters and the investigation of their effective influence for different biomasses. It was observed that, as the reaction severity increases (high temperatures and long residence times), there are more mass transfers from the feedstock towards the liquid phase $[83,87,88]$. However, at high temperatures and long retention times, a lower concentration of reactive soluble compounds could be available in the recycled PW; indeed, these substances could be more involved in decarboxylation reactions to form gaseous products and in re-polymerization reactions to aggregate into the hydrochar matrix during the first HTC step [76]. Future works should systematically investigate the influence of the feedstock nature, and thus, of its macro-constituents during PW recirculation at different temperature, residence time, and solid loads. Solid to water ratio directly affects organic compound concentration in PW and thus its reactivity. The amount of water in HTC should be such that it ensures the occurrence of hydrothermal reactions for the whole biomass sample as well as sufficient heat and mass transfer [91]. Experiments were usually carried out with a biomass to water ratio of $1: 4$ to $1: 10$ [43]. When high biomass to water ratios are used, large concentrations of reactive by-products will be present in the liquid medium; therefore, liquid to solid pathways could be likely to start earlier, leading to an increase in hydrochar yield after few recirculation steps [92-94].

Hydrolysis reactions could intensify and result in higher carbonization rates when more water is used; thus, the PW, if recirculated, could increase the availability in the liquid phase of energy dense particles, which could be responsible for higher HHV for the hydrochars obtained $[95,96]$. The challenges in understanding the influence of PW recirculation during HTC are also related to the lack of studies using advanced analytical methods, such as HPLC or more sophisticated techniques. Analytical methods such as Fourier transform ion-cyclotron resonance mass spectrometer could help to shed a better light on PW compositions and its variation during recirculation steps [43,97]. Hydrochars obtained after PW recycling should also be characterized in terms of surface chemistry and morphology [66]. The combustion behavior of hydrochars should be analyzed in order 
to assess how organic compounds in PW could affect their reactivity after recirculation. Kinetic studies should be promoted to evaluate the order, interactions, and severities of the reactions induced by the recirculation in HTC, despite their complexity that is also related to the different nature of the feedstock. Computational fluid dynamic studies together with kinetic modeling could provide a better insight into the reaction mechanisms and prove the experimental results. The carbonization of biomass can be improved by using acid catalysts which facilitate hydrolysis [98]; however, the application of catalyst in the hydrothermal process is limited by the costs associated with the use and recovery of the catalyst $[43,99]$, unless it is dissolved in the liquid phase and recirculated in the process together with the PW. Since the HTC liquid phase, even after several recirculation steps, contains nutrients (i.e., nitrogen and phosphorus compounds), minerals, and dissolves organics, it can be an interesting substrate for anaerobic digestion, reducing the organic matter content while producing biomethane [100]. Combination of HTC PW recirculation and anaerobic digestion of the resulting liquid phase could be a win strategy for a cleaner and more cost effective valorization of wet waste biomass. The recirculation of PW could increase the overall energy efficiency, by recovering the energy "contained" in the aqueous medium, and reducing the energy use related to water consumptions treatments. Therefore, it becomes imperative to carry out a techno-economic assessment of the PW recirculation strategy to make the methodology even broader, sustainable, and perfectly suited to cleaner HTC production processes.

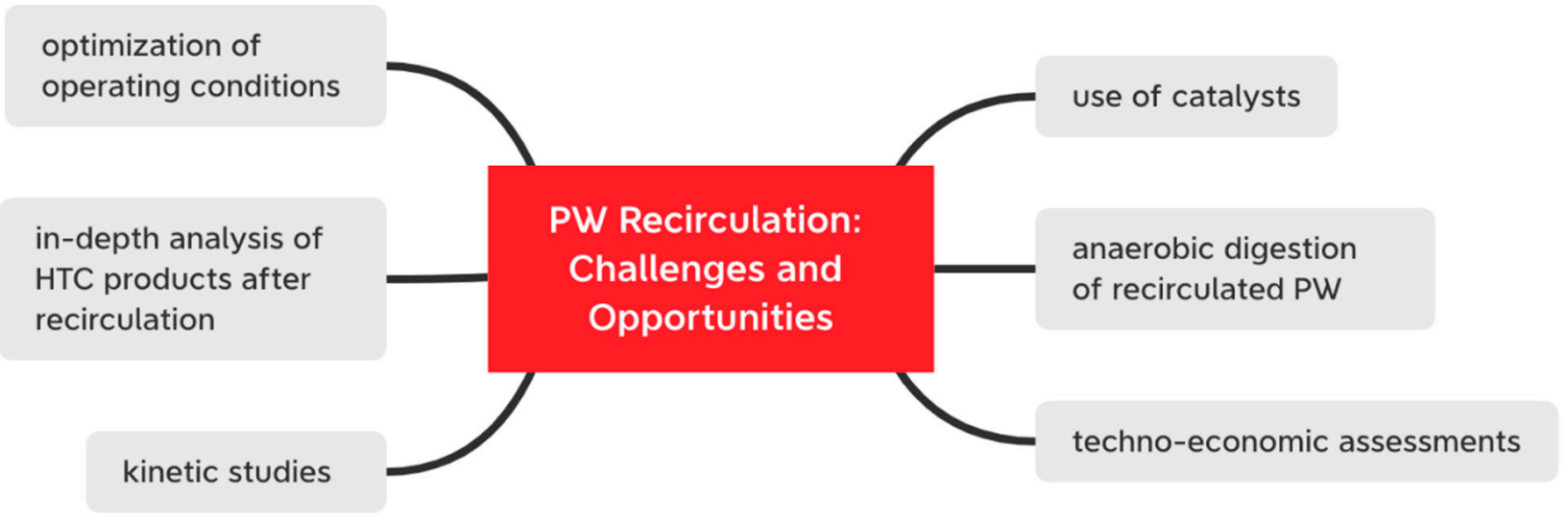

Figure 3. Challenges and research opportunities for PW recirculation during HTC of waste biomass.

\section{Conclusions}

The PW recirculation during HTC could represent a viable and valuable method for the successful sustainable implementation of waste biomass for bio-energy production. More investigations are needed to characterize the HTC products generated after certain previously established recirculation cycles and evaluate the potential benefits for the environment and economic saving. In this review paper, the current knowledge on PW recirculation was reviewed and challenges were presented to identify future directions of PW recirculation HTC strategies. PW recirculation could increase hydrochar mass yield and improve its energy properties. Organic acids concentrated in recycled PW could enhance hydrolysis reactions increasing the concentration of reactive organics in the liquid phase. These soluble compounds could be involved in liquid to solid reactions and contribute to hydrochar mass yields. Dehydration and decarboxylation reactions are promoted by recirculation due to the increased concentration of organic acids in recycled PW. Further deoxygenation of biomass and the increase of carbon content in hydrochars during recirculation could lead to a slight increase in the HHV of solid products. Effects of PW recirculation on HTC products are strictly related to the biomass nature and operating conditions. Future studies are needed in order to detect the influence of process parameters on hydrochar formation during recycling of PW as reaction medium starting from different 
types of feedstock. Solid and liquid phases obtained from HTC with recirculated PW should be characterized by advanced analytical methods to gain a better understanding of reactions promoted during the recirculation. Once reliable knowledge is obtained, the potential advantages of the PW recirculation strategy should be finally evaluated from a techno-economic view, to understand the effective environmental and economic impacts for a cleaner production system of renewable solid biofuels via HTC.

Author Contributions: Conceptualization, A.P., M.V. and A.M.; resources, A.M.; data curation, M.V.; writing-original draft preparation, A.P. and M.V.; writing-review and editing, M.V. and A.M.; visualization, A.M.; supervision, A.M.; project administration, A.M.; funding acquisition, A.M. All authors have read and agreed to the published version of the manuscript.

Funding: The author Maurizio Volpe gratefully acknowledge PON AIM Action Plan on the frame of PON R\&I 2014/2020 for financial support.

Institutional Review Board Statement: Not applicable, as the present study did not involve humans or animals.

Conflicts of Interest: The authors declare no conflict of interest.

\section{References}

1. Yilmaz, S.; Selim, H. A review on the methods for biomass to energy conversion systems design. Renew. Sustain. Energy Rev. 2013, 25, 420-430. [CrossRef]

2. McKendry, P. Energy production from biomass (part 2): Conversion technologies. Bioresour. Technol. 2002, 83, 47-54. [CrossRef]

3. Lee, M.; Lin, Y.L.; Te Chiueh, P.; Den, W. Environmental and energy assessment of biomass residues to biochar as fuel: A brief review with recommendations for future bioenergy systems. J. Clean. Prod. 2020, 251, 119714. [CrossRef]

4. Ibarra-Gonzalez, P.; Rong, B.G. A review of the current state of biofuels production from lignocellulosic biomass using thermochemical conversion routes. Chin. J. Chem. Eng. 2019, 27, 1523-1535. [CrossRef]

5. Volpe, R.; Messineo, S.; Volpe, M.; Messineo, A. Catalytic effect of char for tar cracking in pyrolysis of citrus wastes, design of a novel experimental set up and first results. Chem. Eng. Trans. 2016, 50, 181-186.

6. Luz, F.C.; Volpe, M.; Fiori, L.; Manni, A.; Cordiner, S.; Mulone, V.; Rocco, V. Spent Coffee Enhanced Biomethane Potential via an Integrated Hydrothermal Carbonization-Anaerobic Digestion Process. Bioresour. Technol. 2018, 256, $102-109$.

7. Sawatdeenarunat, C.; Surendra, K.C.; Takara, D.; Oechsner, H.; Khanal, S.K. Anaerobic Digestion of Lignocellulosic Biomass: Challenges and Opportunities; Elsevier Ltd.: Amsterdam, The Netherlands, 2015; Volume 178, ISBN 1808956354.

8. Panwar, N.L.; Kothari, R.; Tyagi, V.V. Thermo chemical conversion of biomass-Eco friendly energy routes. Renew. Sustain. Energy Rev. 2012, 16, 1801-1816. [CrossRef]

9. Dhyani, V.; Bhaskar, T. A comprehensive review on the pyrolysis of lignocellulosic biomass. Renew. Energy 2018, 129, 695-716. [CrossRef]

10. Basu, P. Biomass Gasification and Pyrolysis; Elsevier: Oxford, UK, 2010; ISBN 9780123749888.

11. Gopu, C.; Gao, L.; Volpe, M.; Fiori, L.; Goldfarb, J.L. Valorizing municipal solid waste: Waste to energy and activated carbons for water treatment via pyrolysis. J. Anal. Appl. Pyrolysis 2018, 133, 48-58. [CrossRef]

12. Saha, N.; Volpe, M.; Fiori, L.; Volpe, R.; Messineo, A.; Reza, M.T. Cationic dye adsorption on hydrochars of winery and citrus juice industries residues: Performance, mechanism, and thermodynamics. Energies 2020, 13, 4686. [CrossRef]

13. Merzari, F.; Goldfarb, J.; Andreottola, G.; Mimmo, T.; Volpe, M.; Fiori, L. Hydrothermal carbonization as a strategy for sewage sludge management: Influence of process withdrawal point on hydrochar properties. Energies 2020, 13, 2890. [CrossRef]

14. Chen, W.T.; Haque, M.A.; Lu, T.; Aierzhati, A.; Reimonn, G. A perspective on hydrothermal processing of sewage sludge. Curr. Opin. Environ. Sci. Health 2020, 14, 63-73. [CrossRef]

15. Magdeldin, M.; Kohl, T.; De Blasio, C.; Järvinen, M.; Park, S.W.; Giudici, R. The BioSCWG project: Understanding the trade-offs in the process and thermal design of hydrogen and synthetic natural gas production. Energies 2016, 9, 838. [CrossRef]

16. Ponnusamy, V.K.; Nagappan, S.; Bhosale, R.R.; Lay, C.H.; Duc Nguyen, D.; Pugazhendhi, A.; Chang, S.W.; Kumar, G. Review on sustainable production of biochar through hydrothermal liquefaction: Physico-chemical properties and applications. Bioresour. Technol. 2020, 310, 123414. [CrossRef]

17. Gollakota, A.R.K.; Kishore, N.; Gu, S. A review on hydrothermal liquefaction of biomass. Renew. Sustain. Energy Rev. 2018, 81, 1378-1392. [CrossRef]

18. He, C.; Chen, C.L.; Giannis, A.; Yang, Y.; Wang, J.Y. Hydrothermal gasification of sewage sludge and model compounds for renewable hydrogen production: A review. Renew. Sustain. Energy Rev. 2014, 39, 1127-1142. [CrossRef]

19. Kruse, A. Hydrothermal biomass gasification. J. Supercrit. Fluids 2009, 47, 391-399. [CrossRef]

20. Pavlovič, I.; Knez, Ž.; Škerget, M. Hydrothermal reactions of agricultural and food processing wastes in sub- and supercritical water: A review of fundamentals, mechanisms, and state of research. J. Agric. Food Chem. 2013, 61, 8003-8025. [CrossRef] 
21. Volpe, M.; Fiori, L. From olive waste to solid biofuel through hydrothermal carbonisation: The role of temperature and solid load on secondary char formation and hydrochar energy properties. J. Anal. Appl. Pyrolysis 2017, 124, 63-72. [CrossRef]

22. Merzari, F.; Lucian, M.; Volpe, M.; Andreottola, G.; Fiori, L. Hydrothermal carbonization of biomass: Design of a bench-Scale reactor for evaluating the heat of reaction. Chem. Eng. Trans. 2018, 65, 43-48.

23. Lucian, M.; Volpe, M.; Gao, L.; Piro, G.; Goldfarb, J.L.; Fiori, L. Impact of hydrothermal carbonization conditions on the formation of hydrochars and secondary chars from the organic fraction of municipal solid waste. Fuel 2018, 233, 257-268. [CrossRef]

24. Lucian, M.; Volpe, M.; Fiori, L. Hydrothermal carbonization kinetics of lignocellulosic agro-wastes: Experimental data and modeling. Energies 2019, 12, 516. [CrossRef]

25. Wang, R.; Wang, C.; Zhao, Z.; Jia, J.; Jin, Q. Energy recovery from high-ash municipal sewage sludge by hydrothermal carbonization: Fuel characteristics of biosolid products. Energy 2019, 186, 115848. [CrossRef]

26. Park, K.Y.; Lee, K.; Kim, D. Characterized hydrochar of algal biomass for producing solid fuel through hydrothermal carbonization. Bioresour. Technol. 2018, 258, 119-124. [CrossRef] [PubMed]

27. Regmi, P.; Luis, J.; Moscoso, G.; Kumar, S.; Cao, X.; Mao, J.; Schafran, G. Removal of copper and cadmium from aqueous solution using switchgrass biochar produced via hydrothermal carbonization process. J. Environ. Manag. 2012, 109, 61-69. [CrossRef] [PubMed]

28. Rodríguez Correa, C.; Ngamying, C.; Klank, D.; Kruse, A. Investigation of the textural and adsorption properties of activated carbon from HTC and pyrolysis carbonizates. Biomass Convers. Biorefinery 2018, 8, 317-328. [CrossRef]

29. Volpe, M.; Fiori, L.; Merzari, F.; Messineo, A.; Andreottola, G. Hydrothermal carbonization as an efficient tool for sewage sludge valorization and phosphorous recovery. Chem. Eng. Trans. 2020, 80, 199-204.

30. Marin-Batista, J.D.; Mohedano, A.F.; Rodriguez, J.J.; de La Rubia, M.A. Energy and phosphorous recovery through hydrothermal carbonization of digested sewage sludge. Waste Manag. 2020, 105, 566-574. [CrossRef]

31. Becker, G.C.; Wüst, D.; Köhler, H.; Lautenbach, A.; Kruse, A. Novel approach of phosphate-reclamation as struvite from sewage sludge by utilising hydrothermal carbonization. J. Environ. Manag. 2019, 238, 119-125. [CrossRef]

32. Shi, Y.; Luo, G.; Rao, Y.; Chen, H.; Zhang, S. Hydrothermal conversion of dewatered sewage sludge: Focusing on the transformation mechanism and recovery of phosphorus. Chemosphere 2019, 228, 619-628. [CrossRef]

33. Volpe, M.; Goldfarb, J.L.; Fiori, L. Hydrothermal carbonization of Opuntia ficus-indica cladodes: Role of process parameters on hydrochar properties. Bioresour. Technol. 2018, 247, 310-318. [CrossRef] [PubMed]

34. Volpe, M.; Fiori, L.; Volpe, R.; Messineo, A. Upgrading of Olive Tree Trimmings Residue as Biofuel by Hydrothermal Carbonization and Torrefaction: A Comparative Study. Chem. Eng. Trans. 2016, 50, 13-18.

35. Khan, T.A.; Saud, A.S.; Jamari, S.S.; Rahim, M.H.A.; Park, J.W.; Kim, H.J. Hydrothermal carbonization of lignocellulosic biomass for carbon rich material preparation: A review. Biomass Bioenergy 2019, 130, 105384. [CrossRef]

36. Pauline, A.L.; Joseph, K. Hydrothermal carbonization of organic wastes to carbonaceous solid fuel-A review of mechanisms and process parameters. Fuel 2020, 279, 118472. [CrossRef]

37. Peterson, A.A.; Vogel, F.; Lachance, R.P.; Fröling, M.; Antal, M.J.; Tester, J.W. Thermochemical biofuel production in hydrothermal media: A review of sub- and supercritical water technologies. Energy Environ. Sci. 2008, 1, 32-65. [CrossRef]

38. Hitzl, M.; Corma, A.; Pomares, F.; Renz, M. The hydrothermal carbonization (HTC) plant as a decentral biorefinery for wet biomass. Catal. Today 2015, 257, 154-159. [CrossRef]

39. Leng, L.; Zhou, W. Chemical compositions and wastewater properties of aqueous phase (wastewater) produced from the hydrothermal treatment of wet biomass: A review. Energy Sour. Part A Recovery Utilization Environ. Effects 2018, 40, 2648-2659. [CrossRef]

40. Becker, R.; Dorgerloh, U.; Paulke, E.; Mumme, J.; Nehls, I. Hydrothermal carbonization of biomass: Major organic components of the aqueous phase. Chem. Eng. Technol. 2014, 37, 511-518. [CrossRef]

41. Langone, M.; Basso, D. Process waters from hydrothermal carbonization of sludge: Characteristics and possible valorization pathways. Int. J. Environ. Res. Publ. Health 2020, 17, 6618. [CrossRef]

42. Berge, N.D.; Ro, K.S.; Mao, J.; Flora, J.R.V.; Chappell, M.A.; Bae, S. Hydrothermal Carbonization of Municipal Waste Streams. Environ. Sci. Technol. 2011, 45, 5696-5703. [CrossRef]

43. Leng, S.; Leng, L.; Chen, L.; Chen, J.; Chen, J.; Zhou, W. The effect of aqueous phase recirculation on hydrothermal liquefaction/carbonization of biomass: A review. Bioresour. Technol. 2020, 318, 124081. [CrossRef] [PubMed]

44. Zhuang, X.; Zhan, H.; Song, Y.; He, C.; Huang, Y.; Yin, X.; Wu, C. Insights into the evolution of chemical structures in lignocellulose and non-lignocellulose biowastes during hydrothermal carbonization (HTC). Fuel 2019, 236, 960-974. [CrossRef]

45. Shen, Y. A review on hydrothermal carbonization of biomass and plastic wastes to energy products. Biomass Bioenergy 2020, 134, 105479. [CrossRef]

46. Wang, R.; Jin, Q.; Ye, X.; Lei, H.; Jia, J.; Zhao, Z. Effect of process wastewater recycling on the chemical evolution and formation mechanism of hydrochar from herbaceous biomass during hydrothermal carbonization. J. Clean. Prod. 2020, $277,123281$. [CrossRef]

47. Antero, R.V.P.; Alves, A.C.F.; de Oliveira, S.B.; Ojala, S.A.; Brum, S.S. Challenges and alternatives for the adequacy of hydrothermal carbonization of lignocellulosic biomass in cleaner production systems: A review. J. Clean. Prod. 2020, 252, 119899. [CrossRef]

48. Reza, M.T.; Freitas, A.; Yang, X.; Coronella, C.J. Wet Air Oxidation of Hydrothermal Carbonization (HTC) Process Liquid. ACS Sustain. Chem. Eng. 2016, 4, 3250-3254. [CrossRef] 
49. Stobernack, N.; Mayer, F.; Malek, C.; Bhandari, R. Evaluation of the energetic and environmental potential of the hydrothermal carbonization of biowaste: Modeling of the entire process chain. Bioresour. Technol. 2020, 318, 124038. [CrossRef]

50. Wang, F.; Yi, W.; Zhang, D.; Liu, Y.; Shen, X.; Li, Y. Anaerobic co-digestion of corn stover and wastewater from hydrothermal carbonation. Bioresour. Technol. 2020, 315, 123788. [CrossRef]

51. Fernandez, S.; Srinivas, K.; Schmidt, A.J.; Swita, M.S.; Ahring, B.K. Anaerobic digestion of organic fraction from hydrothermal liquefied algae wastewater byproduct. Bioresour. Technol. 2017, 247, 250-258. [CrossRef]

52. Brown, A.E.; Finnerty, G.L.; Camargo-valero, M.A.; Ross, A.B. Bioresource Technology Valorisation of macroalgae via the integration of hydrothermal carbonisation and anaerobic digestion. Bioresour. Technol. 2020, 312, 123539. [CrossRef]

53. Kruse, A.; Funke, A.; Titirici, M.-M. Hydrothermal conversion of biomass to fuels and energetic materials. Curr. Opin. Chem. Biol. 2013, 17, 515-521. [CrossRef]

54. Reza, M.T.; Uddin, M.H.; Lynam, J.G.; Hoekman, S.K.; Coronella, C.J. Hydrothermal carbonization of loblolly pine: Reaction chemistry and water balance. Biomass Convers. Biorefinery 2014, 4, 311-321. [CrossRef]

55. Kang, S.; Li, X.; Fan, J.; Chang, J. Characterization of hydrochars produced by hydrothermal carbonization of lignin, cellulose d-xylose, and wood meal. Ind. Eng. Chem. Res. 2012, 51, 9023-9031. [CrossRef]

56. McKendry, P. Energy production from biomass (part 1): Overview of biomass. Bioresour. Technol. 2002, 83, 37-46. [CrossRef]

57. Wang, T.; Zhai, Y.; Zhu, Y.; Li, C.; Zeng, G. A review of the hydrothermal carbonization of biomass waste for hydrochar formation: Process conditions, fundamentals, and physicochemical properties. Renew. Sustain. Energy Rev. 2018, 90, 223-247. [CrossRef]

58. Wang, S.; Dai, G.; Yang, H.; Luo, Z. Lignocellulosic biomass pyrolysis mechanism: A state-of-the-art review. Prog. Energy Combust. Sci. 2017, 62, 33-86. [CrossRef]

59. Volpe, M.; Messineo, A.; Mäkelä, M.; Barr, M.R.; Volpe, R.; Corrado, C.; Fiori, L. Reactivity of cellulose during hydrothermal carbonization of lignocellulosic biomass. Fuel Proc. Technol. 2020, 206, 106456. [CrossRef]

60. Fang, Z.; Sato, T.; Smith, R.L.; Inomata, H.; Arai, K.; Kozinski, J.A. Reaction chemistry and phase behavior of lignin in hightemperature and supercritical water. Bioresour. Technol. 2008, 99, 3424-3430. [CrossRef]

61. Hoekman, S.K.; Broch, A.; Robbins, C. Hydrothermal carbonization (HTC) of lignocellulosic biomass. Energy Fuels 2011, 25, 1802-1810. [CrossRef]

62. Sevilla, M.; Fuertes, A.B. The production of carbon materials by hydrothermal carbonization of cellulose. Carbon 2009, 47, 2281-2289. [CrossRef]

63. Kim, D.; Lee, K.; Park, K.Y. Upgrading the characteristics of biochar from cellulose, lignin, and xylan for solid biofuel production from biomass by hydrothermal carbonization. J. Ind. Eng. Chem. 2016, 42, 95-100. [CrossRef]

64. Reza, M.T.; Rottler, E.; Herklotz, L.; Wirth, B. Hydrothermal carbonization (HTC) of wheat straw: Influence of feedwater pH prepared by acetic acid and potassium hydroxide. Bioresour. Technol. 2015, 182, 336-344. [CrossRef]

65. Lynam, J.G.; Coronella, C.J.; Yan, W.; Reza, M.T.; Vasquez, V.R. Acetic acid and lithium chloride effects on hydrothermal carbonization of lignocellulosic biomass. Bioresour. Technol. 2011, 102, 6192-6199. [CrossRef]

66. Arauzo, P.J.; Olszewski, M.P.; Wang, X.; Pfersich, J.; Sebastian, V.; Manyà, J.; Hedin, N.; Kruse, A. Assessment of the effects of process water recirculation on the surface chemistry and morphology of hydrochar. Renew. Energy 2020, 155, 1173-1180. [CrossRef]

67. Wang, F.; Wang, J.; Gu, C.; Han, Y.; Zan, S.; Wu, S. Effects of process water recirculation on solid and liquid products from hydrothermal carbonization of Laminaria. Bioresour. Technol. 2019, 292, 121996. [CrossRef] [PubMed]

68. Parthasarathy, P.; Narayanan, S.K. Effect of hydrothermal carbonization reaction parameters on. Environ. Prog. Sustain. Energy 2014, 33, 676-680.

69. Chen, X.; Ma, X.; Peng, X.; Lin, Y.; Wang, J.; Zheng, C. Effects of aqueous phase recirculation in hydrothermal carbonization of sweet potato waste. Bioresour. Technol. 2018, 267, 167-174. [CrossRef]

70. Köchermann, J.; Görsch, K.; Wirth, B.; Mühlenberg, J.; Klemm, M. Hydrothermal carbonization: Temperature influence on hydrochar and aqueous phase composition during process water recirculation. J. Environ. Chem. Eng. 2018, 6, 5481-5487. [CrossRef]

71. Kambo, H.S.; Minaret, J.; Dutta, A. Process water from the hydrothermal carbonization of biomass: A waste or a valuable product? Waste Biomass Valoriz. 2018, 9, 1181-1189. [CrossRef]

72. Becker, R.; Dorgerloh, U.; Helmis, M.; Mumme, J.; Diakité, M.; Nehls, I. Hydrothermally carbonized plant materials: Patterns of volatile organic compounds detected by gas chromatography. Bioresour. Technol. 2013, 130, 621-628. [CrossRef]

73. Leng, S.; Li, W.; Han, C.; Chen, L.; Chen, J.; Fan, L.; Lu, Q.; Li, J.; Leng, L.; Zhou, W. Aqueous phase recirculation during hydrothermal carbonization of microalgae and soybean straw: A comparison study. Bioresour. Technol. 2020, $298,122502$. [CrossRef] [PubMed]

74. Stemann, J.; Putschew, A.; Ziegler, F. Hydrothermal carbonization: Process water characterization and effects of water recirculation. Bioresour. Technol. 2013, 143, 139-146. [CrossRef] [PubMed]

75. Kabadayi Catalkopru, A.; Kantarli, I.C.; Yanik, J. Effects of spent liquor recirculation in hydrothermal carbonization. Bioresour. Technol. 2017, 226, 89-93. [CrossRef] [PubMed]

76. Picone, A.; Volpe, M.; Giustra, M.G.; Di Bella, G.; Messineo, A. Hydrothermal carbonization of lemon peel waste: Preliminary results on the effects of temperature during process water recirculation. Appl. Syst. Innov. 2021, 4, 19. [CrossRef] 
77. Axelsson, L.; Franzén, M.; Ostwald, M.; Berndes, G.; Lakshmi, G.; Ravindranath, N.H. Perspective: Jatropha cultivation in southern India: Assessing farmers' experiences. Biofuels Bioprod. Biorefining 2012, 6, 246-256. [CrossRef]

78. Sevilla, M.; Fuertes, A.B. Chemical and structural properties of carbonaceous products obtained by hydrothermal carbonization of saccharides. Chem. A Eur. J. 2009, 15, 4195-4203. [CrossRef]

79. Benavente, V.; Calabuig, E.; Fullana, A. Upgrading of moist agro-industrial wastes by hydrothermal carbonization. J. Anal. Appl. Pyrolysis 2015, 113, 89-98. [CrossRef]

80. Arauzo, P.J.; Olszewski, M.P.; Kruse, A. Hydrothermal carbonization brewer's spent grains with the focus on improving the degradation of the feedstock. Energies 2018, 11, 3226. [CrossRef]

81. Gao, L.; Volpe, M.; Lucian, M.; Fiori, L.; Goldfarb, J.L. Does Hydrothermal Carbonization as a Biomass Pretreatment Reduce Fuel Segregation of Coal-Biomass Blends During Oxidation? Energy Convers. Manag. 2019, 181, 93-104. [CrossRef]

82. Poerschmann, J.; Baskyr, I.; Weiner, B.; Koehler, R.; Wedwitschka, H.; Kopinke, F.-D. Hydrothermal carbonization of olive mill wastewater. Bioresour. Technol. 2013, 133, 581-588. [CrossRef]

83. Nizamuddin, S.; Baloch, H.A.; Griffin, G.J.; Mubarak, N.M.; Bhutto, A.W.; Abro, R.; Mazari, S.A.; Ali, B.S. An overview of effect of process parameters on hydrothermal carbonization of biomass. Renew. Sustain. Energy Rev. 2017, 73, 1289-1299. [CrossRef]

84. Nakason, K.; Panyapinyopol, B.; Kanokkantapong, V.; Viriya-empikul, N.; Kraithong, W.; Pavasant, P. Characteristics of hydrochar and liquid fraction from hydrothermal carbonization of cassava rhizome. J. Energy Inst. 2018, 91, 184-193. [CrossRef]

85. Akhtar, J.; Saidina Amin, N. A review on operating parameters for optimum liquid oil yield in biomass pyrolysis. Renew. Sustain. Energy Rev. 2012, 16, 5101-5109. [CrossRef]

86. Lu, X.; Pellechia, P.J.; Flora, J.R.V.; Berge, N.D. Influence of reaction time and temperature on product formation and characteristics associated with the hydrothermal carbonization of cellulose. Bioresour. Technol. 2013, 138, 180-190. [CrossRef] [PubMed]

87. Mau, V.; Quance, J.; Posmanik, R.; Gross, A. Phases' characteristics of poultry litter hydrothermal carbonization under a range of process parameters. Bioresour. Technol. 2016, 219, 632-642. [CrossRef]

88. Sabio, E.; Álvarez-Murillo, A.; Román, S.; Ledesma, B. Conversion of tomato-peel waste into solid fuel by hydrothermal carbonization: Influence of the processing variables. Waste Manag. 2016, 47, 122-132. [CrossRef]

89. Maniscalco, M.P.; Volpe, M.; Messineo, A. Hydrothermal carbonization as a valuable tool for energy and environmental applications: A review. Energies 2020, 13, 4098. [CrossRef]

90. Kalderis, D.; Kotti, M.S.; Méndez, A.; Gascó, G. Characterization of hydrochars produced by hydrothermal carbonization of rice husk. Solid Earth 2014, 5, 477-483. [CrossRef]

91. Knežević, D.; Van Swaaij, W.; Kersten, S. Hydrothermal conversion of biomass. II. Conversion of wood, pyrolysis oil, and glucose in hot compressed water. Ind. Eng. Chem. Res. 2010, 49, 104-112. [CrossRef]

92. Knežević, D.; van Swaaij, W.P.M.; Kersten, S.R.A. Hydrothermal Conversion of Biomass: I, Glucose Conversion in hot compressed water. Ind. Eng. Chem. Res. 2009, 48, 4731-4743. [CrossRef]

93. Li, M.; Li, W.; Liu, S. Hydrothermal synthesis, characterization, and $\mathrm{KOH}$ activation of carbon spheres from glucose. Carbohydr. Res. 2011, 346, 999-1004. [CrossRef] [PubMed]

94. Favas, G.; Jackson, W.R. Hydrothermal dewatering of lower rank coals. 1: Effects of process conditions on the properties of dried product. Fuel 2003, 82, 53-57. [CrossRef]

95. Sermyagina, E.; Saari, J.; Kaikko, J.; Vakkilainen, E. Hydrothermal carbonization of coniferous biomass: Effect of process parameters on mass and energy yields. J. Anal. Appl. Pyrolysis 2015, 113, 551-556. [CrossRef]

96. Liu, Z.; Quek, A.; Balasubramanian, R. Preparation and characterization of fuel pellets from woody biomass, agro-residues and their corresponding hydrochars. Appl. Energy 2014, 113, 1315-1322. [CrossRef]

97. Jarvis, J.M.; Billing, J.M.; Corilo, Y.E.; Schmidt, A.J.; Hallen, R.T.; Schaub, T.M. FT-ICR MS analysis of blended pine-microalgae feedstock HTL biocrudes. Fuel 2018, 216, 341-348. [CrossRef]

98. Hamid, S.B.A.; Teh, S.J.; Lim, Y.S. Catalytic hydrothermal upgrading of $\alpha$-cellulose using iron salts as a lewis acid. BioResources 2015, 10, 5974-5986. [CrossRef]

99. Heidari, M.; Dutta, A.; Acharya, B.; Mahmud, S. A review of the current knowledge and challenges of hydrothermal carbonization for biomass conversion. J. Energy Inst. 2019, 92, 1779-1799. [CrossRef]

100. Pagés-Díaz, J.; Huiliñir, C. Valorization of the liquid fraction of co-hydrothermal carbonization of mixed biomass by anaerobic digestion: Effect of the substrate to inoculum ratio and hydrochar addition. Bioresour. Technol. 2020, 317, 123989. [CrossRef] 